\title{
FORMAÇÃO DO CORPO DOCENTE DOS CURSOS DE GRADUAÇÃO EM CONTABILIDADE NO BRASIL: UMA ANÁLISE CRÍTICA
}

\author{
Valcemiro Nossa \\ Contador \\ Mestre e Doutorando em Controladoria e Contabilidade - FEA-USP \\ Professor da Universidade Federal do Espírito Santo - UFES
}

INTRODUÇÃO

A principal organização que deve preparar os profissionais do futuro é a Instituição de Ensino Superior (IES). Neste sentido, precisa estar atenta às transformações que ocorrem no ambiente em que está inserida e adaptar-se para a formação de estudantes capazes de serem agentes das mudanças exigidas no futuro.

No Brasil, infelizmente, o ensino superior foi, ao longo dos anos, sendo sucateado em nome da democratização de oportunidades. Prédios, equipamentos e, principalmente, professores foram improvisados para que tivesse um número maior de cursos e vagas. A preocupação com a educação no Brasil parece não ter sido levada em conta. Essa questão é levantada por Oliveira (apud Costa, p. 3-4) quando argumenta que: "A educação nunca foi levada devidamente a sério nem pela sociedade, nem pelo governo brasileiro, As escolas e as universidades, o saber, mesmo o saber aplicado, jamais, em nossa história, receberam da sociedade e dos poderes públicos uma forma de atuação continuada". Apesar de já ter passado uma década, essas palavras ainda tem uma conotação social.

No caso específico de ensino de Contabilidade será que a situação é diferente? Vários são os trabalhos que abordam esse assunto. E a conclusão que se tem é de que as escolas não estão cumprindo às exigências do campo de avanço profissional contábil. ludícibus e Marion (1986, p. 51-53) assentam que a situação é delicada e apontam como principais deficiências na metodologia do ensino de Contabilidade Introdutória; proliferação das instituições de ensino e órgãos de classe; e falta de exame de suficiência de âmbito nacional para o exercício da profissão.

Dentre as deficiências apresentadas, a que este artigo pretende abordar é a falta de preparo do corpo docente da Contabilidade. A opção por um trabalho desta natureza decorre da importância da qualidade na educação para o desenvolvimento da sociedade em geral e da relevância do ensino de Contabilidade como área específica de interesse na formação de profissionais, cujo desempenho é essencial ao bom funcionamento e aos resultados de todo tipo de organização.

A melhoria na qualidade de ensino não depende somente das mudanças curriculares e estruturais das instituições de ensino superior, mas principalmente, da seriedade, dedicação e compromisso assumido pelos professores na capacidade de formar bons profissionais e não apenas informá-los sobre alguns conteúdos.

Os professores de uma instituição são um dos principais agentes de mudanças no ensino. De nada adiantará ter-se um currículo adequado, um programa bem definido, muitos recursos financeiros, etc., se o corpo docente não estiver qualificado para ensinar a matéria com dedicação e compromisso. "Qualquer disciplina que for dada, o professor dá o que ele sabe e da maneira que sabe."

No ensino da Contabilidade, geralmente grande parte dos professores é recrutada entre profissionais de sucesso (!) em seu ramo de atuação que, em sua maioria, estão despreparados para o magistério, não tendo noção do que é exigido para formação de alunos.

O professor não deve estar preocupado apenas em passar para o aluno os conhecimentos que sabe, mas fazer o aluno aprender a aprender e para isso é preciso estar preparado.

\footnotetext{
${ }^{1}$ MARTINS, Eliseu. Pronunciamento como membro de Comissão Examinadora de defesa de tese de doutoramento, em 30/10/98, na Faculdade de Economia, Administração e Contabilidade da Universidade de São Paulo.
} 
Preocupados com essa situação professores e profissionais ${ }^{2}$ tem apresentado artigos e trabalhos em revistas, seminários e congressos destacando os problemas relacionados à qualificação e formação do contador. Essas evidências levam a formulação dos seguintes questionamentos:

1. Por que o corpo docente dos cursos de Ciências Contábeis, em sua maioria, possui uma formação deficiente?

2. Quais são as propostas para a melhoria da formação dos professores dos cursos de Ciências Contábeis?

Em decorrência das questões apresentadas, o objetivo geral deste artigo é identificar as principais causas do sofrível desempenho de grande parte dos professores de Contabilidade, bem como levantar propostas para superação desse preocupante problema.

Para o desenvolvimento deste estudo, optou-se por uma pesquisa de campo e para isso foi adotada a metodologia de pesquisa empírico-analítica que, segundo Martins, G. A (1994, p. 26), refere-se a abordagens que "privilegiam estudos práticos. Suas propostas tem caráter técnico, restaurador e incrementalista. Tem preocupação com a relação causal entre as variáveis."

A coleta dos dados foi efetuada em dois momentos. Primeiro realizou-se levantamento de dados secundários referentes à titulação e ao regime de trabalho dos docentes de Contabilidade. Foram consultados na Secretaria de Educação Superior (SESu), no MEC em Brasília (DF), os catálogos referentes ao ano de 1997 das Instituições de Ensino Superior (IES) de todas as regiões do Brasil. Esses catálogos foram remetidos pelas instituições à SESu em comprimento à Portaria do MEC no. 971 , de 22/08/97, que exigia informações sobre os dirigentes da Instituição, corpo docente, biblioteca laboratórios, etc. Esse levantamento teve uma abrangência de 256 IES, eqüivalendo a $76 \%$ do total de instituições que possuem cursos de Ciências contábeis no Brasil.

No segundo momento foram efetivadas 12 entrevistas em profundidade (individual) e um encontro de entrevistas em grupo - focus group (com 10 participantes) com pessoas ligadas às seguintes áreas:

- Professores e profissionais especializados em ensino e pesquisa na área de Ciências Contábeis, principalmente autores de livros, de pesquisas, etc;

- Professores e profissionais especializados em ensino e pesquisa na área de Educação;

- Componentes da Comissão de Especialistas de Ensino de Ciências Contábeis (CEE/Contábeis) vinculada à SESu/MEC;

- Presidente do Conselho Federal de Contabilidade;

- Chefes de departamentos de Ciências Contábeis de algumas instituições de Ensino Superior;

- Grupo de professores de Contabilidade que integram a turma especial de docentes no curso de Pós-Graduação (Mestrado) em Controladoria e Contabilidade na Faculdade de Economia, Administração e Contabilidade da Universidade de São Paulo, provenientes de Universidades localizadas em vários estados brasileiros.

A entrevista, em profundidade, admite que o entrevistador interrogue individualmente o entrevistado o torna possível esclarecer dúvidas, tanto em relação à pergunta quanto à resposta. Marconi \& Lakatos (1982, p. 70) preconizam que a entrevista "é um encontro entre duas pessoas, a fim de que uma delas obtenha informações a respeito de determinado assunto, mediante uma conversação de natureza profissional". A técnica de focus group é conceituada por Oliveira \& Freitas (1998, p. 83) como "um tipo de entrevista em profundidade realizada em grupo, cujas reuniões apresentam características definidas quanto a proposta, tamanho, composição e procedimentos de condução. $O$ foco ou o objeto de análise é a interpretação e descrição dos dados pesquisados, o tipo de entrevista utilizada foi a estruturada. Foi elaborado um roteiro contendo nove questões iguais para todos os entrevistados. Segundo Gil (1994, p. 117), a entrevista estruturada desenvolve-se a partir de "uma relação fixa de perguntas, cuja ordem e redação permanece invariável (sic) para todos os entrevistados".

\footnotetext{
${ }^{2}$ MOREIRA (1996); IUDÍCIBUS \& MARION (1986); FAVERO (1992); ONU apud SCMIDT, P. (1996); FRANCO (1992), OLIVEIRA (1995), entre outros.
} 


\section{FORMAÇÃO DO PROFESSOR DO ENSINO SUPERIOR}

A expansão do ensino superior no Brasil foi considerável desde a década de 50 . Esse crescimento aconteceu na forma quantitativa, sem preocupação com os aspectos qualitativos. Aumentaram-se apenas as instituições, os cursos e as vagas.

Para maior visualização dessa expansão do ensino superior no Brasil, é apresentado a seguir a evolução do número de instituições: em 1808 era apenas uma escola de nível superior, a Escola de Cirurgia e Medicina da Bahia; em 1890 eram 14 instituições; em 1930 já eram 86, em 1960 esse número cresceu para 404 e em 1996 o País já contava com 922 Instituições de Ensino Superior.

Na visão de Teixeira (1969, p, 49) as instituições deveriam passar por grandes reformas na qualidade de ensino antes de qualquer ampliação. Quando é abordada a questão do professor da universidade brasileira lembra-se que ele era uma das figuras mais respeitadas e admiradas da nação. Hoje, porém não se pode ter esse mesmo discurso.

Com esse crescimento quantitativo do ensino superior, o descaso com a questão pedagógica evidenciou-se de forma assustadora. Jovens profissionais passaram a ser recrutados sem nenhuma experiência docente e, o mais sério, sem nenhum preparo para o exercício do magistério.

Para ingressar na docência de ensino superior, o professor não tem muitas exigências legais no que se refere à titulação e à formação pedagógica. Nem a antiga Lei de Diretrizes e Bases da Educação - LDB $^{3}$ nem a atual mencionam qualquer exigência sobre a formação didáticopedagógica como pré-requisito para o exercício do magistério superior. $\mathrm{E}$ ainda, quanto à titulação, basta que o professor tenha curso de graduação na área para concorrer à vaga de docente. Resta a cada instituição determinar o seu nível de exigência que a atual LDB faz é de que um terço do corpo docente, pelo menos, deve ter Curso de Mestrado ou Doutorado.

A formação pedagógica ultrapassa o conhecimento do conteúdo que o docente ensina. A falta dessa preparação pode tolher o compromisso do professor com as ações que ele desenvolve com seus alunos, com a instituição em que trabalha e mesmo com a comunidade.

A questão pode ser pior ainda, segundo Schwartzman (1994, p. 151), em algumas áreas do conhecimento tais como Comunicações, Estatística, Biblioteconomia, Administração, Contabilidade, etc., em que há uma tendência de atrair estudantes menos qualificados, que se dirigem aos cursos com pouca ou nenhuma tradição e com menor concorrência no vestibular. Esses estudantes encontram mais tarde grandes dificuldades em obter um trabalho que de alguma forma corresponda aos conteúdos formais das carreiras que escolheram. Como a maioria deles trabalha enquanto estuda, que é um fato normal nesses cursos, não tem problema de encontrar emprego depois de formados. O que eles esperam é que seu diploma possa ser útil para conseguir melhores salários e ter mais oportunidades no mercado de trabalho. É desses estudantes formados que saem a maioria dos novos docentes que vão ingressar no ensino superior.

Com todo esse crescimento no ensino superior, caso não haja professores preparados adequadamente para atender à demanda dos cursos, a qualidade destes tende a declinar. $\mathrm{O}$ que poderia ser considerado como ensino de nível superior, com essa depreciação, pode ser atacado apenas como ensino de nível técnico.

No ensino superior, encontra-se muito a figura do professor transmissor de conhecimento, sem o comprometimento de relacionar o conteúdo específico com o mundo real que aparece fora dos bancos escolares. Acabam desvinculando a teoria da realidade na qual os alunos estão inseridos. O professor deve estimular seus alunos a aprender a aprender. Deve criar um espírito de busca permanente de novas descobertas. Não há dúvidas de que o conhecimento é um processo que deverá estar em constante desenvolvimento. Coisas consideradas como verdades hoje, poderão não ser amanhã. Não se pode dizer que todas as verdades são eternas, pois a realidade se altera e essas mudanças devem ser percebidas pelos professores.

O compromisso do professor com os temas educacionais, num sentido muito mais amplo do que a simples transmissão de conhecimentos ou experiências profissionais, é uma questão sobre a qual o docente deveria estar constantemente em processo de reflexão. Educar, no entanto, é ato consciente e intencional que ultrapassa a etapa do instruir. Um professor de ensino superior

\footnotetext{
${ }^{3}$ A antiga LDB é a Lei no. 5.540/68 e a atual é a Lei no. 9.394/96.
} 
deve avaliar o conhecimento específico de sua área o domínio da habilidade de educar. Somente o professor que busca conhecer intensamente o processo de ensino aprendizagem poderá modificar e aperfeiçoar a sua prática, "seja do ponto de vista de suas etapas, seja das funções requeridas no ato de aprender"(Silveira, 1988, p. 38).

A partir dos primeiros anos da década de 80 , a preocupação com a formação técnica do professor assumiu maior importância nos debates. Sem desconsiderar a questão da formação política do futuro docente, enfatizava-se a necessidade de uma formação técnica que envolvesse tanto o conhecimento específico de determinado campo quanto o conhecimento pedagógico.

A capacitação de qualquer profissional vai muito além dos conhecimentos técnicos propriamente ditos; deve abranger uma gama de outros conhecimentos filosóficos, políticos, éticos, etc. No caso do professor de 3 grau, Vasconcelos (1996, p. 24-34) destaca quatro aspectos para sua formação competente:

\section{a) Formação técnico científica}

Contempla o domínio do conteúdo específico que se deseja ensinar com o entendimento dos aspectos teóricos que cercam o assunto. Não é admitido a um professor que não conheça o assunto o que vai lecionar em sala de aula. $O$ docente deve ter um compromisso com a educação como um todo e não simplesmente com o ensinar sem nenhum comprometimento com os objetivos mais genéricos da tarefa de educar. $O$ conteúdo a ser transmitido deve ter como marca esse envolvimento do professor.

Todo o professor deve conhecer o conteúdo da disciplina sob sua responsabilidade, mas além disso, questionar, recriar, relacionar os diversos conhecimentos e efetivar já nesse momento um processo de iniciação científica em seus alunos, incitando-os a buscarem novos conhecimentos para antigos aprendizados.

Ë importante que o docente esteja num processo incessante de busca na atualização dos conteúdos, para não se consolidar em uma atitude passiva do eterno repetir. Isto permite constituirse em base sólida para novos conhecimentos e novas pesquisas para a investigação científica. A participação em congressos, simpósios, cursos e palestras são algumas maneiras de manter-se atualizado e criar estímulos para a produção científica.

\section{b) Formação prática}

O relacionamento entre teoria e prática é fator de garantia de competência para o exercício da docência universitária. Assim, o professor deve ter conhecimento da prática profissional para a qual seus alunos estão sendo formados. Não há duvida de que o professor que tem os conhecimentos técnico científicos e uma vasta experiência profissional no campo específico de atualização do curso será um docente mais atualizado e, por extensão, com uma visão mais ampla da aplicação da teoria na prática ocupacional futura de seus discípulos.

c) Formação pedagógica

A formação pedagógica do docente de ensino superior vai além do simples dar aulas (Vasconcelos, 1996, p. 28); abrange também aspectos do planejamento de ensino visto como um todo, que é constituído: 1) de objetivos gerais e específicos da instituição e da disciplina lecionada; 2) da caracterização da clientela (aluno); 3) do conhecimento do mercado de trabalho; 4) dos objetivos específicos do processo ensino aprendizagem; 5) da seleção dos conteúdos; 6) das atividades e recursos do ensino aprendizagem; 7) da avaliação de aprendizagem; 8) das possibilidades de construção e reconstrução do conhecimento; e 9) da relação professor aluno.

A maioria dos problemas de ensino relacionados com docentes que dificultam a aprendizagem dos alunos seria, no mínimo, melhorada com maior aperfeiçoamento do professor na área de pedagogia. Professores que nunca passaram por qualquer formação na área especificamente pedagógica, certamente terão agravadas as suas características de um profissional adequado para o ensino. O comprometimento com as questões do ensino e da educação surgem, naturalmente, da competência pedagógica do professor.

d) Forma política

Além dos conhecimentos técnicos, práticos e pedagógicos, o professor deve estar preocupado também com as questões que o cercam, o meio social, político, humano, ético, etc. $O$ docente precisa reconhecer a pessoa do aluno, visualizar o meio onde ele vive. Para isto deve pensar de modo político. Esse compromisso com o aluno em formação será , sem sombra de dúvida, uma das qualidades que toda instituição de ensino deve procurar alcançar e melhorar 
constantemente. Para que o professor exerça sua cidadania num projeto de educação torna-se necessário que ele seja um intelectual crítico capaz de apreender e trabalhar as diferenças visualizadas na sala de aula e, além disso, deve ser ético para mostrar efetivamente sua competência.

A formação escolar é condição necessária, mas não suficiente, para garantir uma atuação comprometida com um projeto educacional em evolução.

Mesmo tendo uma boa formação muitos professores acabam não se dedicando de forma integral às atividades universitárias; por falta de melhores salários e outras condições operacionais, são atraídos para outros mercados de trabalho, principalmente os profissionais liberais. Esse fato já era vivido nas escolas americanas nos anos 50, conforme relata Alexander (1960, p.5) que diz que "melhores oportunidades com melhores salários nas indústrias atraem muitas pessoas que foram treinadas para o ensino". Esse é um dos problemas que assola as Instituições de Ensino Superior no Brasil. Em muitos casos, o professor exerce as atividades de ensino apenas como complemento salarial e em tempo parcial. Neste caso, o docente acaba perdendo o interesse ou fica impossibilitado de aperfeiçoar-se como profissional do ensino. Outra questão que aparece no ensino é o da formação teórica e prática do professor. O problema da defasagem existente entre a preparação ou treinamento oferecido pelas escolas de formação profissional e a realidade da atividade prática futura é um ponto que tem aflorado nas discussões sobre a questão da capacitação para a trabalho. É importante que se tenha uma ligação da teoria com a prática naquilo que é apresentado ao aluno, para que este se sinta seguro em relação ao conteúdo de sua aprendizagem, o qual é imprescindível para sua formação profissional. Para que isso aconteça, no entanto, é necessário que o professor seja conhecedor dessa dialética: teoria e prática.

O que se deve evitar é que um professor, detentor de uma grande vivência profissional específica, tenha poucos conhecimentos teóricos que envolvam essa prática. O fazer repetitivo gera um saber. Daí decorre suas questões diárias, composto de soluções encontradas ao longo da prática de sua profissão. Isso pode tornar-se perigoso para o ensino, pois "muitas vezes a rotina e a repetição fazem o conhecimento prático tornar-se tácito e tão espontâneo que os profissionais não mais refletem sobre o que estão fazendo"(Schon, apud Santos, 1991, p. 323).

Há a necessidade de se ter maior número de professores pesquisadores para que haja permanente a geração de novos conhecimentos. No Brasil, historicamente, a função primordial desempenhada pelas escolas foi a de ensino. A questão do tripé ensino-pesquisa-extensão, que a legislação prevê, atinge apenas $3 \%$ das Universidades brasileiras (Sampaio, 1997, p. 106). Nas instituições de ensino que possuem professores com melhores qualificações, bem como maior número em regime de tempo integral, há uma tendência de maior desenvolvimento de pesquisas.

O professor necessita de algumas características facilitadoras ao correto exercício do magistério que devem ser adquiridas, aperfeiçoadas, atualizadas e adaptadas. Kertész \& Lorenzini (apud Vasconcelos, 1996, p. 40) apresentam algumas dessas características: comunicabilidade, comportamento ético, equilíbrio emocional, criatividade, boa expressão verbal, bom relacionamento interpessoal, comportamento funcional adequado, dentre outras.

Um bom perfil para o professor de $3^{\circ}$ grau é ter num só indivíduo três capacidades igualmente desenvolvidas: 1) a de transmitir os conhecimentos, ou seja, aquele que sabe ensinar; 2) a do critico das relações socio-culturais da sociedade que o cerca e do momento histórico no qual vive; e 3) a do pesquisador, capaz de, por intermédio de estudos sistemáticos e de investigações empíricas, produzir o novo e induzir seu aluno a também criar (Vasconcelos, 1996, p. 10).

Em pesquisa realizada por Cunha, M. I (1989), buscou-se identificar as principais características de um bom professor. Algumas das conclusões a que o estudo levou são aqui apresentadas:

- Quanto aos motivos de estarem no magistério, $60 \%$ dos bons professores afirmaram que foi por razões circunstanciais e não como opção profissional primeira. Por outro lado, disseram que gostam muito do que fazem;

- Há uma influência de atitudes positivas de ex-professores em seus comportamentos como docentes; entretanto, muitos tentam não repetir experiências negativas de ex-professores; 
- Uma segunda influência apontada refere-se ao saber construído em contato com colegas de trabalho, com alunos e de reflexão sobre a sua própria docência, reformulando sua forma de agir e de ser;

- Outro fator de influência no seu modo de ser é a formação pedagógica. Foi percebido que, quanto mais a formação pedagógica responde às necessidades do professor, no momento em que a realiza, mais eles a valorizam;

- Destacou-se também como fator de influência de seu modo de ser, a repetição de práticas das pessoas que admiram, tais como profissionais de alta competência na área em que atuam;

- O professor é a principal fonte do conhecimento sistematizado, demonstrada pela ênfase na exposição oral;

- Quanto à representação que o bom professor faz de sua prática pedagógica, a pesquisadora conclui que:

$\checkmark$ na relação com o ser e o sentir o professor dá grande valor ao prazer de ensinar e à gratificação que sente nas relações com os alunos;

$\sqrt{ }$ na relação com o saber há um destaque significativo na afetividade que o liga à sua matéria de ensino, que leva ao gosto pelo estudo e à possibilidade de produzir conhecimento junto com os alunos;

$\checkmark$ na relação com o fazer há um esforço de coerência entre o que ele faz e o que ele pensa. O fazer do professor é muito intuitivo, não fazendo uma análise reflexiva de sua prática. A prática tende a repetir a prática, pois nem sempre se estabelecem relações claras entre a prática e os pressupostos teóricos que a embasam;

$\sqrt{ }$ as habilidades de ensino manifestadas pelos bons professores durante as observações

foram:

$\sqrt{ }$ quanto á habilidade de organização do contexto da aula: (1) explicita o objetivo do estudo; (2) localiza historicamente o conteúdo ; (3) estabelece relações do conteúdo com outras áreas do saber; (4) usa artifícios verbais para apontar questões fundamentais; (5) apresenta ou escreve o roteiro da aula; (6) referencia materiais de consulta.

$\checkmark$ quanto á habilidade de incentivo à participação do aluno: (1) formula perguntas (de natureza exploratória e/ou encaminhadora; (2) valoriza o dialogo; (3) provoca o aluno para realizar suas próprias perguntas; (4) transfere indagações de um aluno para o outro ou para toda a classe; (5) usa palavras de reforço positivo; (6) aproveita as respostas dos alunos para dar continuidade à aula; (7) ouve as experiências cotidianas dos alunos;

$\checkmark$ quanto à habilidade de tratar a matéria de ensino: (1) esforça-se para tornar a linguagem acadêmica acessível: clareia conceitos, faz analogias, estabelece relação entre causa e efeito, vincula teoria e prática, etc.; (2) usa exemplos; (3) utiliza resultados de pesquisas;

$\checkmark$ quanto à habilidade do uso de linguagem: (1) tem clareza nas explicações através de : uso de terminologia adequada, emprego de voz audível, uso de pausas e silêncios, adoção de entonação de voz variada, etc.; (2) tem senso de humor no trato com os alunos.

Ainda na opinião de pesquisadora, o professor é capaz de apresentar o melhor esquema do conteúdo a ser desenvolvido em aula, mas não conhece procedimentos sobre como fazer o aluno chegar ao mapeamento próprio da aprendizagem que está realizando.

Finalmente, pode-se concordar com Vasconcelos (1996, p. 31) que acredita que:

"o professor, dotado de competência técnica (na área de sua especialidade), de competência prática ( no campo de trabalho ao qual a sua disciplina está ligada), de competência científica (voltada para a construção do novo conhecimento) e de competência pedagógica ( voltada para o fazer pedagógico, construído no seu cotidiano, em sala de aula, mas de modo não ocasional e sim metodologicamente desenhado), será certamente um profissional da Educação e não simplesmente alguém que, exercendo uma função, não se compromete com ela, com seus aspectos mais formais e específicos".

\section{A FORMAÇÃO DO PROFESSOR DE CONTABILIDADE DOS CURSOS DE CIÊNCIAS CONTÁBEIS}

A escola de comércio foi o marco inicial do ensino da Contabilidade no Brasil. Teixeira (1969, p. 43) argumenta que a escola de comércio brasileira foi criada por simples tratado, ao 
contrário da criação da escola de comércio de Harvard, que primeiro elaborou um estudo completo de todos os relatórios de empresas administrativas e industriais americanas em cerca de oitenta anos de vida. Baseou-se nas decisões dessas empresas a elaboração do material que compôs o acervo da biblioteca. A partir daí, esse material passou a ser estudado e investigado e a Escola de Comércio transformou-se em Universidade. Detalhe: no Brasil fizeram-se escolas até sem biblioteca!

Nota-se um grande crescimento quantitativo dos cursos de Ciências Contábeis no Brasil, principalmente na última década, período em que praticamente duplicou o número de cursos. Só para ter uma idéia, em 1973 existiam 131 cursos superiores de Contabilidade; em 1976, eram 166; em 1986 esse número já alcançava 384 cursos.

A proliferação de instituições de ensino de Contabilidade, principalmente particulares, é apontada por ludícibus e Marion (1986, p. 53) como uma das causas da má qualidade do ensino de Ciências Contábeis. Aumentou-se o número de instituições, porém, sem nenhuma preocupação com os aspectos qualitativos dos cursos. Ex-alunos e profissionais liberais com pouco ou nenhum conhecimento pedagógico passaram a fazer parte do corpo docente dessas escolas. A maioria desses professores não possuem outros cursos além da graduação em Ciências Contábeis. Em alguns casos, chega-se ao extremo do docente só ter curso de graduação em área não contábil.

Para Favero (1987, p. 399), a contratação de docentes sem qualquer experiência em magistério e sem cursos de metodologia de ensino superior causa impactos negativos na qualidade do ensino e no futuro profissional da área contábil.

Muitos são os trabalhos que abordam a situação do ensino superior de Contabilidade no Brasil. A maioria das pesquisas menciona que o aluno que conclui o curso de Ciências Contábeis não está preparado para o mercado de trabalho. Uma das causas apontadas pelos autores é a inadequada e desatualizada formação dos professores.

Mereceu destaque o trabalho do Conselho Federal de Contabilidade (CFC) elaborado por um Grupo de Estudos em 1985, visando `a implantação do currículo mínimo no curso de Ciências Contábeis. No estudo, uma das falhas mais evidenciadas refere-se ao despreparo dos professores. Essas falhas segundo o Grupo de Estudos, só serão resolvidas mediante a reciclagem do corpo docente, com a criação de novos cursos de especialização, mestrado e doutorado (CFC, 1985).

Favero (1987, p. 373) ao analisar os resultados da avaliação feita pelos professores dos cursos de Ciências Contábeis no estado do Paraná, percebeu que a maior incidência de problemas está ligada: ao despreparo do corpo docente; à deficiência curricular, à falta de integração entre professores; e à falta de infra-estrutura adequada. $\mathrm{Na}$ opinião dos alunos entrevistados $(23,8 \%)$, uma das razões que dificultam a realização do curso é o desestímulo dos professores.

Ao observar a falta de interesse de alguns anos por determinadas disciplinas, Schwes (1985, p. 33) examinou o problema e constatou que esse fato, muitas vezes, tem relação com a organização seqüencial do conteúdo ou com a maneira como este é abordado. Verificou também pouca preocupação com a integração entre as disciplinas do currículo dos cursos. "Há professores que desconhecem os programas das disciplinas que vêm após a sua, ou das que precedem". Nota-se, neste caso, a falta de conhecimento mais profundo das disciplinas e a desintegração entre os docentes.

A falta de treinamento para os docentes dos cursos de Ciências Contábeis também é constatada pela Organização das Nações Unidas - ONU como uma das maiores deficiências na educação contábil no Brasil, de acordo com a pesquisa realizada em 1994 (apud Schmidt, 1996, p. 336).

Ainda sobre a influência na má qualidade do ensino no Brasil, Franco (1993, p. 810-811) destaca como principais problemas que envolvem os professores os seguintes:

- Carência de corpo docente qualificado, na maioria das escolas, em virtude de baixa remuneração, de falta de estímulo ao mestre e de absoluta ausência de planejamento para sua formação pedagógica e aperfeiçoamento cultural;

- Insuficiência de programas de mestrado e de treinamento pedagógico de professores em todos os níveis;

- Falta de programas de educação continuada, para atualização técnica e cultural de professores, à semelhança do que se propõe instituir para profissionais militantes; 
- Falta de vivência profissional de inúmeros docentes de disciplinas técnico-profissionais, o que os impede de serem objetivos em suas aulas, mesmo as teorias, por desconhecerem a aplicação prática;

- Inexistência de critérios, na maioria das escolas, para avaliação de produtividade intelectual e pedagógica de professores, medida que se faz necessária, periodicamente, para manter o corpo docente estimulado e atualizado.

- Inexistência, na maioria das escolas, de teste de capacitação técnico-profissional e de prova de nível cultural (exame de suficiência), para ingresso do professor na carreira, o que deveria ser exigido, nos moldes do que se pretende instituir, para a habilitação legal do contador.

No ingresso de professores no ensino superior, não é levada em conta, por parte da maioria das faculdades, a capacitação técnico-profissional e pedagógica, fundamental para a formação de um corpo docente qualificado. Há instituições que até exigem avaliações da capacitação dos docentes, porém as realizam com o necessário cuidado e eficiência. Em muitos casos é mera formalidade. Por outro lado, os docentes, porém não as realizam com o necessário de cuidado e eficiência. Em muitos casos é mera formalidade. Por outro lado, os docentes não possuem recursos para acompanhar programas permanentes de atualização ou participar de congresso, convenções e outros eventos culturais que lhes permitam o aperfeiçoamento constante dos conhecimentos. Uma das maneiras de resgatar a imagem do docente, tão deteriorada atualmente, é "remunerá-lo condignamente e conceder-lhe condições necessárias para desempenhar seus deveres, dele exigindo, em contrapartida, prova de capacitação para o exercício deste importante mister. Crises econômicas, políticas e sociais decorrem, geralmente, de crise cultural (educação deficiente) podendo-se interpretar o professor como estreio e propulsor do desenvolvimento"(Franco, 1997, p. 7).

Para o professor sem criatividade, que segue um ritmo tradicional há décadas, o conteúdo ministrado perde-se e a exploração prospectiva não tem espaço. Muitos cursos foram abertos nos últimos anos e não há docentes suficientemente preparados para atender a todas as escolas.

A área contábil ainda encontra um outro agravante que é o setor empresarial oferecendo melhores condições de trabalho aos profissionais mais qualificados, e retirando do ensino aqueles que poderiam dar maior impulso ao seu desenvolvimento. A substituição por outro professor de mesmo nível normalmente fica prejudicada. Como há necessidade de nova contratação, acabam por assumira a vaga profissionais sem qualquer experiência no magistério e, em muitos casos, sem comprometimento com o ensino, já que possuem outras atividades profissionais fora da escola (Favero, 1992, p. 43-46)

Mas, afinal, como deve ser a atuação do professor de Contabilidade em sala de aula?

Pessoas são influenciadas por pessoas. No processo de ensino, esse processo não é diferente. O corpo docente de uma instituição tem grande influência na formação acadêmica de seus alunos. No processo ensino-aprendizagem o professor é o agente ativo e deve ter como papel o elemento facilitador desse processo. Por isso é fundamental a sua formação docente e profissional. Algumas características podem gerar influência sobre os alunos de forma positiva ou negativa, como por exemplo: ética profissional, comportamento, metodologia utilizada, conteúdo ministrado, personalidade, qualificação, experiência, dedicação, etc. Neste sentido, o docente deve ser honesto, demonstrar cultura e competência, servindo até de exemplos para seus alunos.

Muitas das dificuldades de aprendizagem encontradas pelos alunos da área contábil podem estar no processo de comunicação e no processo motivacional. "O professor tem de ter a capacidade e o dom de provocar atitudes sobre os conteúdos de ensino e sobre o próprio aprendizado, por meio de uma comunicação motivadora. Deve dar condições ao aluno para que este, ao sair da influência exercida, tenha atitudes tão favoráveis quanto possíveis, baseando-se num comportamento visível e positivo"(Schwez, 1997, p. 33).

No processo de comunicação, o professor deve ser verdadeiro e inspirar confiança. Um dos problemas básicos que há comunicação é que aquilo que o receptor capta pode não ser exatamente o que o emissor de fato quis transmitir. Esse caso pode ocorrer principalmente quando o professor da área contábil está voltado totalmente ao ensino tecnicista, esquecendo o lado humanista (Schwez, 1997, p. 34).

O processo motivacional compreendido pelo professor deve permitir aos alunos a aquisição de comportamentos que assegurem um eficiente ajustamento pessoal e sócio-cultural.

Caderno de Estudos, São Paulo, FIPECAFI, nº 21 - Maio a Agosto/1999 
Schwez (1997, p. 36-37) apresenta em seu artigo vários estímulos para a motivação. Destacam-se aqui apenas os relacionados ao papel do professor na área contábil:

$\sqrt{ }$ apresentar de tal maneira sua disciplina que, ao aprende-la, o aluno esteja, ao mesmo tempo, aprimorando seus instrumentos de trabalho mental (didática, planejamento, metodologia);

$\sqrt{ }$ aceitar críticas e criticar-se a si mesmo; aceitar diversos pontos de vista estruturados, lógicos, sólidos; reavaliar-se e atualizar-se;

$\checkmark$ aprender a ensinar a sua disciplina;

$\checkmark$ conhecer os conteúdos das disciplinas anterior e posterior à sua;

$\checkmark$ aceitar que os alunos são indivíduos, e não números, e de diferentes características, e saber agir para cada caso com bom-senso e coerência;

$\checkmark$ prover feedback imediato e específico às respostas do aluno;

$\checkmark$ dar ao aluno oportunidades de selecionar e seqüencializar assuntos a serem estudados, de maneira que ele sinta o mais envolvido possível na atividade educativa;

$\sqrt{ }$ usar comunicação dinâmica, correta, facilitadora de compreensão e motivadora;

$\checkmark$ usar somente aqueles itens de testes que sejam relevantes para os objetivos, coerentes e claros;

$\checkmark$ expressar genuína satisfação em ver o aluno;

$\sqrt{ }$ reconhecer que as respostas dos alunos, sejam corretas ou incorretas, são tentativas de aprender, e acompanhá-las de comentários positivos;

$\checkmark$ propiciar ao aluno formas de autocontrolar a extensão da instrução recebida;

$\checkmark$ permitir que o aluno movimente-se tão à vontade quanto suas características de idade, desde que não atrapalhe suas aulas;

$\sqrt{ }$ saber aprender com os alunos;

$\checkmark$ desenvolver suas aulas demonstrando confiança, satisfação e segurança;

$\sqrt{ }$ ter boa apresentação pessoal.

\section{CURSOS DE PÓS-GRADUAÇÃO EM CONTABILIDADE NO BRASIL}

Até meados da década de 60 , os cursos de pós-graduação eram ministrados nas Universidades de maneira livre, sem legislação própria. A primeira regulamentação ocorreu por meio do Parecer no. 977/65, do extinto Conselho Federal da Educação (Cunha, L.A., 1974, p. 67)> No entanto, suas principais características foram evidenciadas por intermédio da Lei de Diretrizes e Bases no, 5.540, de 28 de novembro de 1968.

Em 19655, haviam 23 cursos de Mestrados e 10 de Doutorado em todas as áreas de conhecimento. Em 1977, eram 609 e 213, respectivamente. Atualmente, são 1.275 em nível de mestrado e 677 em nível de Doutorado, sendo que a maioria desses cursos estão concentrados na Região Sudeste.

O ensino de pós-graduação tem por objetivo a formação do pessoal qualificado para o exercício do magistério superior e para as atividades de pesquisa.

Quanto a pós-graduação em Contabilidade no Brasil a situação não é muito tranquilizadora. Em nível stricto sensu, são poucos os cursos existentes. Em nível lato sensu, embora sejam muitos os cursos em praticamente todo o Brasil, nem sempre são de qualidade adequada para a formação do professor.

As condições de implantação de cursos de pós-graduação stricto sensu, no entanto, muitas vezes são complexas, pois como observam ludícibus e Marion (1993, p.2), "a falta de professores em número suficiente em tempo integral, se na graduação é prejudicial, na pósgraduação, pode ser fatal por causa de problemas de orientação de teses de mestrado e doutorado".

No brasil, atualmente, são três os Cursos de mestrado e Doutorado que estão plenamente reconhecidos e aprovados pela Fundação Coordenação de Aperfeiçoamento de Pessoal de Nível Superior - CAPES, todos localizados na Região Sudeste. Vale ressaltar que outros cursos estão em fase inicial de implantação. A seguir serão descritos os programas existentes. 


\section{PROGRAMA DE PÓS-GRADUAÇÃO EM CONTROLADORIA E CONTABILIDADE DA FEA/USP}

A Faculdade de Economia, Administração e Contabilidade da Universidade de São Paulo - FEA/USP - foi criada em 1946, para suprir o ensino superior de Contabilidade e Atuária, Administração e Economia e formar profissionais altamente qualificados.

Desde 1970, o Departamento de Contabilidade e Atuária da FEA/USP passou a oferecer o programa de Pós-graduação stricto sensu em Controladoria e Contabilidade em nível de mestrado e a partir de 1978, em nível de Doutorado.

O programa é oferecido aos alunos graduados em nível superior (no caso de Mestrado) e aos mestres (no caso de Doutorado) para a formação de pesquisadores e de docentes.

No programa de Mestrado foram defendidas até 1997 e no Doutorado 53 teses. A média anual de defesas nos últimos cinco anos foi de 11 dissertações e 5 teses. Dos 53 alunos que receberam também a titulação de Mestre nesse mesmo programa.

\section{PROGRAMA DE PÓS-GRADUAÇÃO EM CIÊNCIAS FINANCEIRAS E CONTÁBEIS DA PU/SP}

A PUS/SP - Pontifícia Universidade Católica de São Paulo - implantou o programa de Pós-graduação em Ciências Financeiras e Contábeis, em nível de Mestrado, no ano de 1978 e foi apoiado por professores da Universidade de São Paulo. A finalidade do programa era promover a capacitação de pessoal para atuar em docência do ensino superior e em pesquisa na área contábil.

Inicialmente, tinha como público alvo os próprios professores da PUC/SP, mas acabou por atrair também executivos de empresas privadas e públicas que buscavam um melhor preparo profissional. Isto fortaleceu a formação técnica em detrimento da produção acadêmica. A pequena quantidade de trabalhos defendidos levou o programa, em 1991, a rever seus objetivos, iniciandose, então, um plano estratégico que visava a sua integração à excelência acadêmica da Universidade.

Até 1997 foram defendidas nesse programa de mestrado 41dissertações, sendo 11 destas no último ano.

\section{PROGRAMA DE PÓS-GRADUAÇÃO EM CIÊNCIAS CONTÁBEIS DA FAF/UERJ}

O curso de Mestrado em Ciências Contábeis foi criado em 1970 na Fundação Getúlio Vargas na cidade do Rio de Janeiro (FGV - RJ). Em 1991, foi reestruturado e transferido para a FAF/UERJ - Faculdade de Administração e Finanças da Universidade Estadual do Rio de Janeiro.

No período de 1970 a 1990, quando o curso funcionava na FGV-RJ, foram defendidas 27 dissertações. Enquanto que na UERJ, de 1991 a 1997, houve 45 trabalhos defendidos, sendo 14 destas no último ano.

Os três programas juntos (FEA/USP, PUC-SP e FAF/UERJ) titularam até 1997 o total de 226 mestres e 53 doutores em Contabilidade. Verifica-se que esse número de profissionais titulados é muito pequeno para suprir a demanda de professores nos cursos de graduação e pósgraduação em Ciências Contábeis.

Conforme informações disponibilizadas pela CAPES, existiam em maio de 1998, em tramitação nesse órgão, nove processos requerendo aprovação de programas de Pós-Graduação em Contabilidade, em nível de Mestrado.

Os cursos de pós-graduação lato sensu ou cursos de especialização em Contabilidade estão presentes em praticamente quase todos os estados brasileiros. Muitos deles, inclusive, voltados especificamente para a formação de professores do magistério superior, com carga horária mínima de 360 horas, de acordo com a Resolução no. 12/83 do Conselho Federal de Educação, que exige pelo menos 60 horas de Metodologia de Ensino Superior. A maioria desses cursos, no entanto, seguem uma tendência legalista que, segundo Maseto (1988, p.227), são ministrados unicamente para se cumprir um dispositivo legal, tendo em vista a obtenção de um certificado. 
ludícibus e Marion (1993, p.3) ressaltam que esses cursos "não são tidos de boa qualidade, principalmente pelas precariedades de recursos e escassez de professores titulados".

\section{TITULAÇÃO DE PROFESSORES DE CONTABILIDADE}

São vários os trabalhos que apresentam dados referentes à titulação dos professores de Contabilidade. Alguns estudos foram realizados em nível nacional, outros regionais e outros ainda referente à disciplina. Dentre esses, podemos destacar os de Costa $^{4}$ (1988), Favero ${ }^{5}$ (1987), Pacheco Filho ${ }^{6}$ (1988), Coelho et alii ${ }^{7}$ (1998) e Theóphilo et alii ${ }^{8}$ (1998).

Observa-se através dessas pesquisas que, nos cursos de Ciências Contábeis são minoria os professores com cursos de Mestrado e Doutorado. Há grande concentração de professores com cursos de graduação e/ou especialização.

Após a tabulação dos dados coletados nos catálogos da Instituições de Ensino Superior verificou-se que continua existindo uma grande aglomeração de professores dos cursos de Ciências Contábeis que possuem apenas cursos de graduação e/ou especialização.

$\mathrm{Na}$ tabela a seguir são apresentados os percentuais de professores por titulação em cada uma das Regiões do Brasil:

Professores dos cursos de Ciências Contábeis Distribuídos por Titulação - 1997 (em \% de professores em relação ao total geral)

\begin{tabular}{|l|l|l|l|l|l|l|}
\hline Titulação & Norte & Nordeste & $\begin{array}{l}\text { Centro- } \\
\text { Oeste }\end{array}$ & Sudeste & Sul & $\begin{array}{l}\text { Todas as } \\
\text { regiões }\end{array}$ \\
\hline $\begin{array}{l}\text { Graduado em Ciências } \\
\text { Contábeis }\end{array}$ & 1,0 & 3,9 & 1,6 & 8,3 & 6,7 & 21,5 \\
\hline $\begin{array}{l}\text { Graduado em outras } \\
\text { áreas }\end{array}$ & 0,0 & 0,1 & 0,0 & 0,6 & 0,1 & 0,8 \\
\hline $\begin{array}{l}\text { Especialista em } \\
\text { Ciências Contábeis }\end{array}$ & 2,1 & 6,1 & 5,0 & 21,7 & 13,2 & 48,1 \\
\hline $\begin{array}{l}\text { Especialista em outras } \\
\text { áreas }\end{array}$ & 0,1 & 0,7 & 0,4 & 7,0 & 3,0 & 11,2 \\
\hline $\begin{array}{l}\text { Mestrado em Ciências } \\
\text { Contábeis }\end{array}$ & 0,3 & 1,4 & 0,7 & 7,7 & 1,9 & 12,0 \\
\hline $\begin{array}{l}\text { Mestrado em outras } \\
\text { áreas }\end{array}$ & 0,0 & 0,4 & 0,0 & 1,6 & 0,7 & 2,7 \\
\hline $\begin{array}{l}\text { Doutorado em Ciências } \\
\text { Contábeis }\end{array}$ & 0,0 & 0,3 & 0,2 & 2,8 & 0,4 & 3,7 \\
\hline Total por região & 3,5 & 12,9 & 7,9 & 49,7 & 26,0 & 100,0 \\
\hline
\end{tabular}

Fonte: catálogos das Instituições de Ensino Superior enviados ao MEC/SESu, 1997

A Região Sudeste responde por aproximadamente $50 \%$ das instituições que possuem cursos de Ciências Contábeis e consequentemente, por $50 \%$ dos professores de Contabilidade. Encontra-se nesta região também o maior percentual de professores com títulos de Mestrado e Doutorado. Isto, talvez, possa ser justificado pelo fato de ser o local onde se encontram os cursos de Contabilidade em nível de pós-graduação stricto sensu. Isso não acontece em todas as regiões. A Região Norte, por exemplo, não apresenta docentes com o título de Doutor.

${ }^{4}$ COSTA, J.M.R. da. Pesquisa realizada em nível nacional.

${ }^{5}$ FAVERO, H. L. Pesquisa com abrangência restrita ao Estado do Paraná.

${ }_{7}^{6}$ PACHECO FILHO, L.G. Pesquisa restrita ao município de Belo Horizonte.

${ }^{7}$ COELHO, C.R.A. et alii - Pesquisa restrita à disciplina de Contabilidade de Custos e com abrangência nacional.

${ }^{8}$ THEÓPHILO, C.R. et alii - pesquisa restrita à disciplina Teoria da Contabilidade e com abrangência nacional. 
Das instituições pesquisadas no Brasil, somente $19 \%$ dos professores cursaram pósgraduação stricto sensu. Os demais $(81 \%)$ possuem apenas cursos de especialização $(59 \%)$ ou graduação $(22 \%)$, conforme se apresenta no gráfico a seguir.

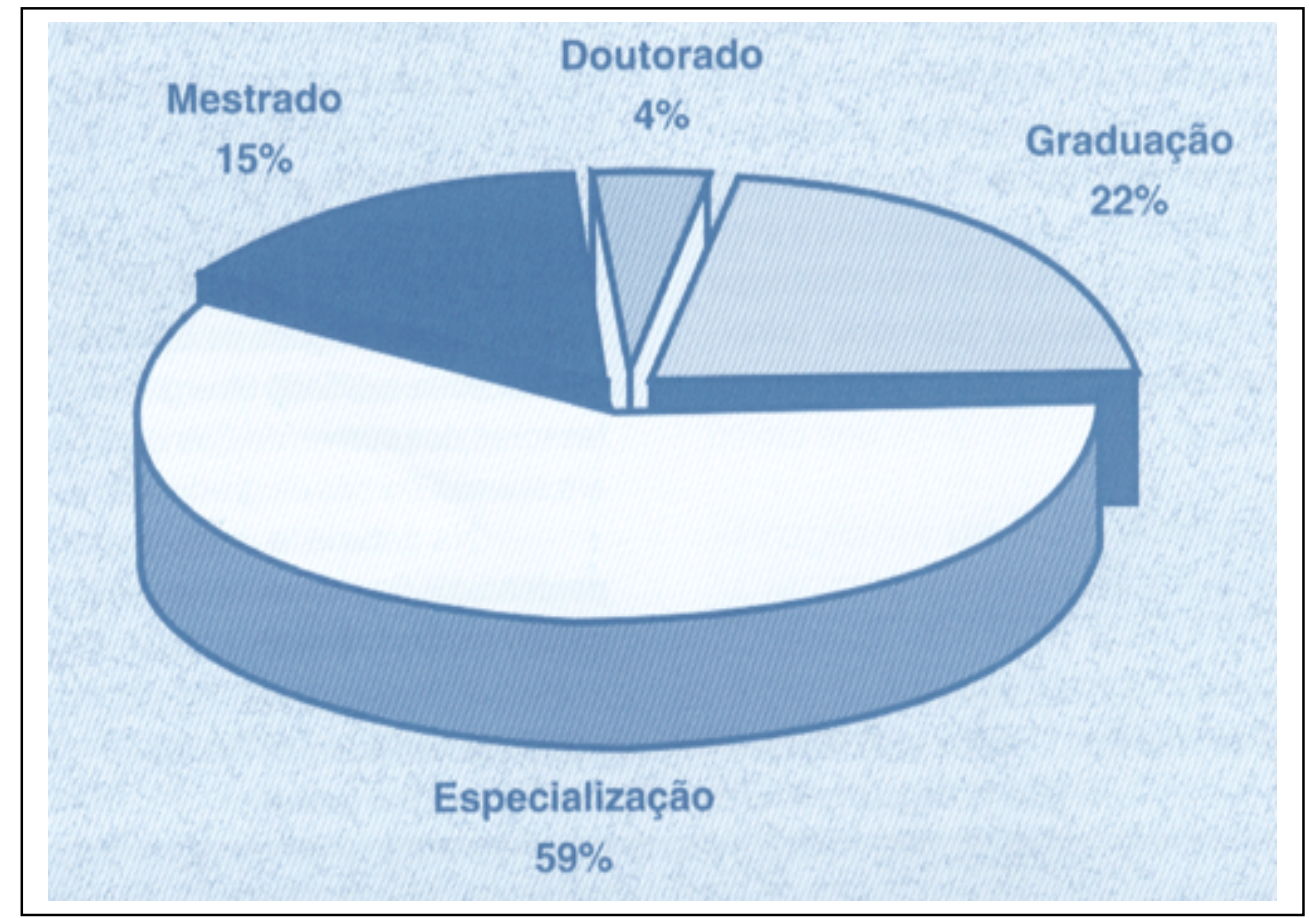

Verifica-se que a titulação dos professores de Contabilidade está bem abaixo da média geral de todos os cursos superiores do País. Enquanto que o total de cursos possui $41 \%$ dos docentes com o título de Mestrado ou Doutorado, o de Ciências Contábeis tem apenas 19\%.

Vale ressaltar que de acordo com a nova Lei de Diretrizes e Bases da Educação as Universidades devem ter no mínimo um terço de professores com cursos de Mestrado ou Doutorado.

\section{REGIME DE TRABALHO DOS PROFESSORES DE CONTABILIDADE}

Um outro fator que tem fortes repercussões no ensino é o regime de trabalho dos professores. É pequeno o número de instituições que mantém docentes em regime de tempo integral. Sem essa dedicação, raramente o professor consegue atualizar-se e desenvolver um bom trabalho. ludícibus e Marion (1986, p. 52) argumentam que "são raras as instituições que investem no aperfeiçoamento do seu corpo docente em cursos de pós-graduação, estímulo à pesquisa, cursos de áreas interdisciplinares, participação em congressos..."

A atividade de ensino exige tempo do profissional e o ensino de Contabilidade não foge à regra. Martins, N.S. (1993, p. 19) argumenta que para muitos profissionais da área contábil, a atividade docente é considerada apenas como complemento de renda. O professor sente-se desestimulado de ter essa função como principal fonte de recursos. Muitos necessitam ter um emprego-base fora da Universidade, o que acaba prejudicando a preparação de aulas, realização de pesquisas, atualização de conhecimentos, etc.

Vê-se em várias pesquisas ${ }^{9}$, que há uma predominância de professores em regime de trabalho horista e em tempo parcial. Percebe-se também, uma das características dos cursos de Ciências Contábeis, que permite a seus professores trabalharem em tempo parcial, é que a maioria funcionam em períodos noturnos: o professor trabalha durante o dia em outras atividades e à noite

\footnotetext{
${ }^{9}$ Essas pesquisas são as mesmas citadas no item anterior.
} 
ministra aulas. Segundo Serra Negra (1997, p. 130) $81 \%$ dos cursos de Ciências Contábeis são ministrados exclusivamente à noite, $4 \%$ são diurnos e $15 \%$ funcionam de dia e à noite.

De acordo com os dados coletados nos catálogos das Instituições de Ensino Superior, constata-se que mais da metade dos professores $(84 \%)$ trabalham em regime horista ou em tempo parcial, ou seja, até 39 horas semanais. Na Região sudeste, onde estão concentradas mais da metade das instituições pesquisadas, apenas $9 \%$ dos docentes estão em regime de tempo integral (40 ou mais horas semanais).

Observa-se que há uma distância entre a situação atual e o que está sendo exigido pela nova Lei de Diretrizes e Bases da Educação de que pelo menos um terço dos professores trabalhem em tempo integral.

Há concordância entre os entrevistados de que o fato da maioria dos professores de Contabilidade estar em regime horista ou parcial acaba prejudicando o nível de ensino, porque esses docentes geralmente possuem outras atividades fora da Universidade e se dedicam prioritariamente a elas. Em muitos casos, a sala de aula torna-se um apêndice da atividade principal que é exatamente prática e o professor acaba apenas informando o aluno. Ensina o como fazer e não o porquê fazer.

É fundamental ter professores com dedicação exclusiva na escola, para o desenvolvimento de pesquisas científicas ou mesmo conhecendo a produção científica gerada por outros pesquisadores, bem como lendo livros novos, etc. Por outro lado, nos cursos de Ciências Contábeis torna-se necessário também que haja professores ligados ao mercado de trabalho fora da Universidade, uma vez que este profissional pode trazer muitas situações reais a serem discutidas em sala de aula. Neste caso, o ideal seria ter, concomitantemente, o docente de tempo integral e o de tempo parcial. Este último, inclusive, seria ainda mais útil quando permanecesse algum tempo na escola além do horário de suas aulas.

\section{ALGUMAS CAUSAS DO DESPREPARO DO CORPO DOCENTE DOS CURSOS DE CONTABILIDADE}

A maioria dos docentes dos cursos de Ciências Contábeis tem apresentado um "sofrível" desempenho na área acadêmica, conforme discutido ao longo deste artigo. Diante desse fato, procurou-se investigar as causas desse despreparo do corpo docente. ${ }^{10}$

Após a organização dos dados coletados nas entrevistas, constatou-se que as causas abordadas tiveram diferentes enfoques, conforme se verifica a seguir:

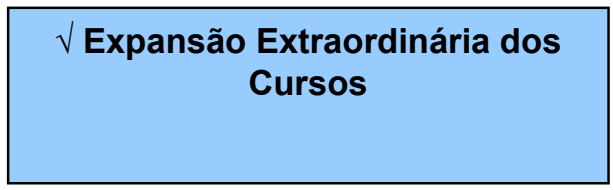

Com a expansão das escolas e dos cursos, não foram encontrados recursos humanos suficientemente preparados para suprir a oferta de vagas, principalmente preparados nas instituições particulares. Valeram-se dos profissionais da comunidade, que transformaram-se em professores, do dia para a noite, sem o devido preparo necessário. Nessa situação, muitos desses docentes passam a não fazer uma reflexão do conteúdo que estão levando para a sala de aula. Só para se uma se ter uma idéia, o curso de Ciências Contábeis duplicou no período de 1986 a 1996, passando de 194 para 384 cursos.

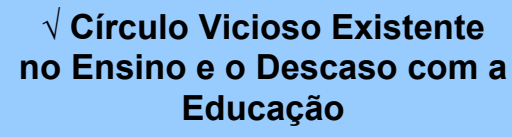

${ }^{10}$ Vale ressaltar que esse não é privilégio dos cursos de Ciências Contábeis. Isso também é visível em outras áreas do conhecimento. 
Ao longo do tempo, foi sendo criado um círculo vicioso em torno do ensino, em função da falta de exigência e avaliações. As escolas não cobram dos professores, os professores não cobram dos alunos, os alunos por sua vez não cobram dos professores e das escolas.

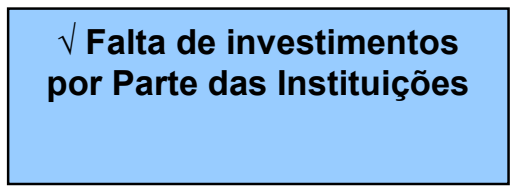

O fato da maioria das instituições superiores particulares estar interessada tão-somente na lucratividade é apontada como outra razão. A maior parte dessas escolas não investem além do mínimo necessário, uma vez que para atingir seus objetivos o que existe já e suficiente.

\section{$\sqrt{ }$ Maior Atração por parte do Mercado Profissional \\ e Falta de Incentivo à \\ Carreira Acadêmica}

A falta de atratividade por parte das escolas, principalmente quanto à remuneração e falta de incentivos para seguir a carreira acadêmica, acaba levando para o mercado de trabalho pessoas que poderiam estar na docência ou mesmo reduzindo a dedicação daqueles que exercem a função do magistério.

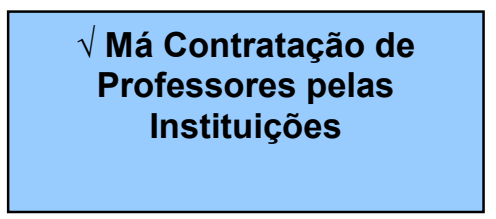

A falta de exigências na contratação dos docentes, por parte da maioria das instituições, que os colocam em sala de aula sem dar condições para que tenham uma capacitação adequada, também é expressada como uma das causas.

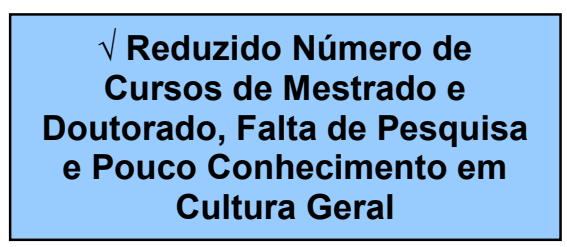

O pequeno número de cursos stricto sensu em Contabilidade, a falta de cultura geral e humanística e a falta de tempo para a pesquisa leva a maioria dos professores a aceitar coisas como verdades absolutas, sem discuti-las. Isto também prejudica o desempenho do professor. 


\section{PROPOSTAS DE MELHORIA DA FORMAÇÃO DO CORPO DOCENTE}

Após a identificação e discussão de algumas causas que contribuem para o despreparo do Professor de Contabilidade, faz-se necessário buscar alternativas para melhorar ou até reverter a situação atual.

Muitos entrevistados entendem que tênues mudanças para a melhoria do ensino já estão acontecendo, principalmente, após a edição da nova Lei de Diretrizes e Bases da Educação. São necessárias, no entanto, serem implementadas outras medidas para que se tenha no futuro um ensino de melhor qualidade. As principais propostas apresentadas são:

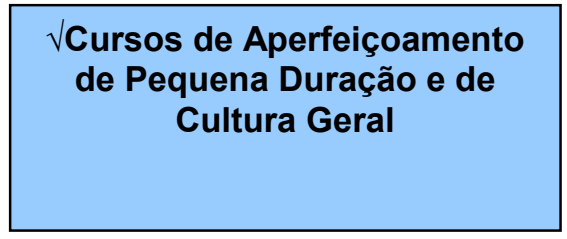

No curto prazo, os Departamentos de Contabilidade devem promover cursos, de pequena duração, nas áreas específicas de atuação do professor, bem como nos aspectos pedagógicos envolvidos. Devem também incentivar os docentes a fazerem cursos de Português, Línguas Estrangeiras, História Econômica, etc., bem como disciplinas de Lógica, Ética, Metodologia de Pesquisa e de Ensino, etc., que certamente ajudam no desenvolvimento do nível de cultura geral e no relacionamento com o aluno.

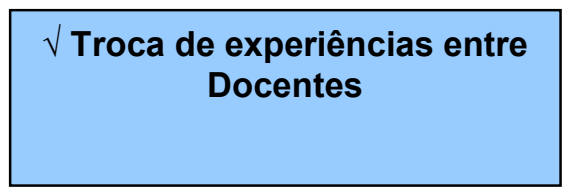

Deve ser implantado, no Departamento de Contabilidade, um espaço para que todos os docentes possam se encontrar, principalmente em tempo integral e os de tempo parcial. Isso permitiria discussões e troca de experiências acadêmicas e de Prática do mercado.

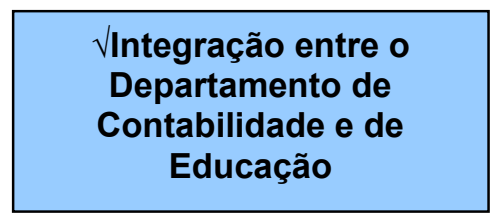

A integração entre os professores do Departamento de Contabilidade e de Educação deve ser instituída para que haja pessoas da área educacional reciclando e discutindo de forma permanente as questões do ensino com os professores da área contábil.

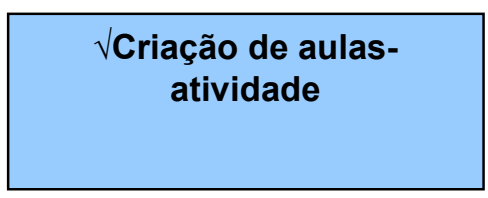

Há a necessidade de que o docente, principalmente o que está em regime de trabalho horista, permaneça na escola além do horário de suas aulas, corrigir trabalhos, fazer pesquisas 
bibliográficas, atender alunos, etc. Para isso é preciso que os responsáveis pelas instituições tomem consciência desse fato e criem as chamadas aulas-atividades, devidamente remuneradas, para que o professor possa desempenhar essas tarefas.

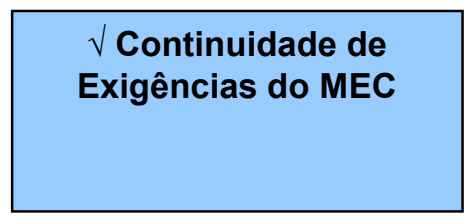

O Ministério da Educação e do Desporto deve continuar com as exigências, proporcionadas no que tange à qualidade do ensino, inclusive punindo aquelas instituições que não deflagrarem um processo de compromisso com a educação. O Exame Nacional de Cursos ('Provão") na área de Contabilidade também provocará uma reflexão daqueles cursos que tiverem um resultado da avaliação desfavorável.

$\sqrt{ }$ Exame de Suficiência Profissional

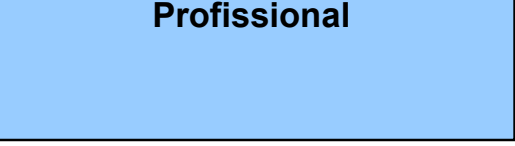

Para desencadear um processo de maior cobrança entre professores, alunos e escolas e elevar o nível de qualidade do ensino deve ser introduzido o Exame de Suficiência Profissional, em que a certificação do curso superior (diploma) não seria mais considerado suficiente para o exercício da profissão. Isso faria com que saísse de uma situação de pura acomodação existente para uma situação de maior compromisso com o ensino-aprendizagem.

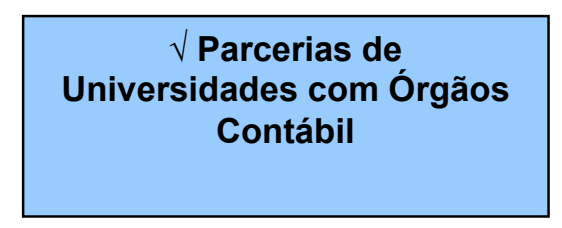

É apontada como proposta, também, a viabilização de parcerias entre as Universidades, que proporcionariam suporte acadêmico, e os Conselhos Regionais e Federal de Contabilidade, que contribuiriam com a criação de estruturas físicas em algumas regiões, inclusive bibliotecas, sistemas de videoconferência, etc., uma vez que estes possuem unidades instaladas em todos os estados do Brasil. Isto permitiria o encurtamento virtual de distâncias, possibilitando uma expansão dos cursos de Mestrado, bem como cursos de curta e média duração.

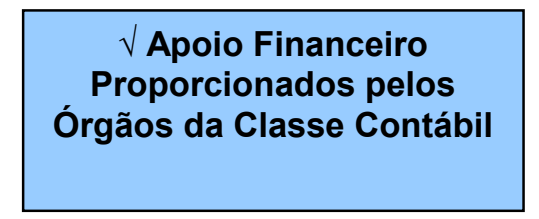

O apoio financeiro concedido pelo Conselho Federal e Regional de Contabilidade para professores e/ou profissionais da área contábil que pretendem cursar pós-graduação (inclusive 
mestrado) é colocada como sugestão para melhorar o desempenho docente. Essa medida é necessária, uma vez que os recursos para bolsas de estudos provenientes dos órgãos financiadores como CAPES, CNPQ, etc., são cada vez menores.

\section{$\sqrt{ }$ Tempo integral para 0 \\ Curso de Ciências Contábeis}

A transferência do curso de Ciências Contábeis do período noturno para tempo integral também traria mudanças na postura da maioria dos professores. Essa proposta se torna extremamente necessária no médio e longo prazo, pois só assim docentes e alunos estariam realmente presentes no ensino e na pesquisa e a partir daí melhor contribuíram com o desenvolvimento da Contabilidade.

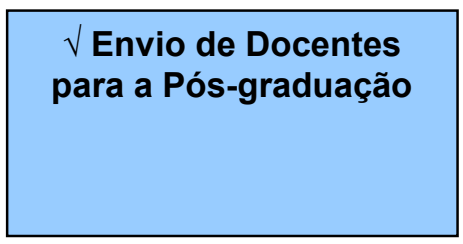

As Instituições de Ensino Superior devem ter sempre o compromisso de enviar docentes e pesquisadores para os cursos de Mestrado e Doutorado, principalmente fora do Brasil, como nos Estados Unidos da América e na Europa. O confronto de idéias provenientes de outros países é "frutífero" à produção científica e evita, inclusive, a endogenia de conhecimentos.

\section{CONCLUSÕES}

A expansão do ensino superior no Brasil foi grande desde a década de 60 . Nos cursos de Ciências Contábeis a situação não foi diferente. Aumentaram o número de instituições, de prédios, de salas, etc. sem a preocupação maior com um ensino de boa qualidade. Para suprir todo o crescimento quantitativo, em muitos casos, foi necessário contratar profissionais do mercado com pouca ou nenhuma experiência na área acadêmica, para suprir a oferta de vagas na atividade docente. Essas e outras causas fizeram com que a maioria dos professores de Contabilidade apresentasse deficiências no processo de ensino-aprendizagem.

As escolas de ensino superior devem realmente assumir o seu papel e dar aos seus docentes oportunidades e condições para capacitação e atualização. É imprescindível a disponibilização de recursos financeiros e o estímulo aos docentes para cursarem pós-graduação, tanto no Brasil como no exterior. Quanto aos professores, é indispensável a conscientização da necessidade de buscar novos conhecimentos, novas técnicas de ensino, enfim, de se comprometerem com a educação.

Espera-se que os responsáveis pelos Departamentos de Contabilidade das Instituições de Ensino Superior, o Ministério da Educação e do Desporto, os representantes da classe contábil, os coordenadores de cursos de pós-graduação stricto e lato sensu, os professores, os alunos, etc. discutiram, reflitam e implementem as sugestões apresentadas nesta pesquisa.

\section{RESUMO}


O presente artigo tem a finalidade de discutir sobre a formação de professores de Contabilidade no Brasil. Inicialmente são apresentados os principais aspectos da formação do professor de ensino superior de maneira geral, bem como especificamente da Contabilidade.

O professor, para ser um profissional da educação deve ser dotado de competência técnica, científica, política e pedagógica.

$\mathrm{Na}$ área contábil, a maioria dos docentes apresentam um sofrível desempenho na execução de suas funções acadêmicas. São minoria os professores com titulação de Mestrado e Doutorado (apenas 19\%). Procurou-se por meio de pesquisa empírica identificar as principais razões e as sugestões de melhoria para essa situação.

Dentre as causas principais, tem-se: expansão extraordinária do número de cursos; círculo vicioso existente no ensino; falta de investimentos por parte das instituições; maior atratividade no mercado profissional; reduzido número de cursos de Mestrado e Doutorado, etc. Como propostas de melhoria são apontadas: cursos de aperfeiçoamento de pequena duração para os professores; troca de experiências entre docentes; integração entre o Departamento de Contabilidade e de Educação; criação de aulas-atividade; introdução do Exame de Suficiência Profissional; tempo integral para os cursos de Ciências Contábeis, dentre outros.

\section{REFERÊNCIAS BIBLIOGRÁFICAS}

Alexander, William M. Are you a good teacher? New York: Holt, 1960.

BRASIL. Conselho Federal da Educação. Resolução no. 12, de 27 outubro de 1983. Documenta. Brasília, n. 275, p. 149-51, nov/1983.

Lei no. 5540, de 28 de novembro de 1968.

Lei no. 9.394, de 20 de dezembro de 1996.

. Ministério da Educação e do Desporto. Portaria no. 971, de 22/08/97.

Disponível: http://www.mec.gov.brl, em 20/03/1998.

COELHO, Cassius R. A..; CHAGAS, José Ferreira \& NOSSA, Valcemiro. O ensino da contabilidade de custos no Brasil. Revista Brasileira de Contabilidade. Ano XXVII, n. 111, mai/jun. 1998.p. 60-79.

CONSELHO Federal de Contabilidade. Relatório da Presidência 1982-1985. Rio de Janeiro: Grupo de Estudos da Legislação do Ensino da Contabilidade, 1985.

COSTA, José Mario Ribeiro da. O Ensino da Contabilidade na universidade brasileira: Quem é e como pensa seu corpo docente. Rio de Janeiro, 1988. Dissertação (Mestrado): Fundação Getúlio Vargas/ISEC.

Caderno de Estudos, São Paulo, FIPECAFI, nº 21 - Maio a Agosto/1999 
CUNHA, Luiz Antonio C. R. A pós-graduação no Brasil: função técnica e função social. Revista de Administração de Empresas. Rio de Janeiro, v. 14, n..5, p. 66-70, set/out. 1974.

FAVERO, Hamilton Luiz. O ensino superior de Ciências Contábeis no Estado do Paraná: um estudo de caso. Rio de Janeiro, 1987. Dissertação (Mestrado): Fundação Getúlio Vargas/ISEC.

Análise crítica do ensino de ciências contábeis. In: CONGRESSO BRASILEIRO DE CONTABILIDADE, 14. Anais. Salvador (BA), v.III, out/1992, p. 40-52.

FRANCO, Hilário. Aprimoramento técnico e cultural de professores e valorização profissional. In: CONGRESSO BRASILEIRO DE CONTABILIDADE, 14. Anais. Salvador, 1992. v. III.

Aprimoramento técnico e cultural de professores e valorização profissional (1992). In: 50 anos de Contabilidade. São Paulo: Atlas, 1993, p. 804-817.

Educação Contábil no Brasil: Problemas e soluções possíveis. Boletim do IBRACON. São Paulo, ano XX, n. 233, out. 1997, p. 4-15.

GIL, Antonio Carlos. Métodos e técnicas de pesquisa social. 4. Ed. São Paulo: Atlas, 1994, 207p.

IUDíCIBUS, Sérgio de \& MARION, José Carlos. As faculdades de ciências contábeis e a formação do contador. Revista Brasileira de Contabilidade. Rio de Janeiro. N. 56, p. 50-56, 1986.

. Considerações sobre os cursos de pós-graduação em contabilidade.

Boletim do IBRACON, ano XVI, n. 186, nov/1993.

MARCONI, Marina de Andrade \& LAKATOS, Eva Maria. Técnicas de pesquisa. São Paulo: Atlas, 1982.

MARTINS, Gilberto de Andrade. Manual para elaboração de monografias e dissertações. 2. Ed. São Paulo: Atlas , 1994, 116p. 
Formação do Corpo Docente dos Cursos de Graduação em Contabilidade no Brasil: 20 Uma Análise Crítica

MARTINS, Norma Sueli. O ensino superior de ciências contábeis nas universidades federais estaduais do Estado do Rio de Janeiro: um estudo de caso. Rio de Janeiro, 1993. Dissertação (Mestrado): Fundação Getúlio Vargas/ISEC. 